ankles. He is very cheerful, and expresses himself as being free from pain. An enema of thin gruel ordered to relieve the bowels.

6th.- -After a seconä enema, which contained some castor oil, had been administered, the bowels were freely relieved, and much flatus expelled. The wounds of the throat are firmly ad herent, and those of the chest are closing. Some slight degree of motion and sensation experienced in the left leg. Pulse soft, steady, and 86-90. He was allowed tish and gravy soup tor dinner, and one glass of sherry.

Sth. - Very free purging has supervened, since which the em physema has much diminished, the face having almost assumed its natural expression. He has since the 7 th taken two grains of calomel, with a quarter of a grain of opium, every four hours. He can to-day flex the left knee, raise the leg, \&c. The chest wounds completely closed by granulations; the sutures from the wound in the throat were removed to day, union being com. plete. To continue calomel pills every six, instead of tvery four, hours. A stomachic draught ordered.

10th. -With some little assistance he raised himself, and is now sitting up in bed reading. The ptosis of the left eyelid is very nearly removed; the left leg daily acquiring renewed vigour, but the superior limb is completely powerless and useless. He complains of feeling in it at times very singular pains. Emphysema very much diminished, most evident about the npper part of the chest. Respiration is regular, and on applying the ear to the right side puerile respiratory sounds are easily defined, and there is no question but that the upper portion of the left lung has some amount of functional activity; the condition of the lower portion of the same lung cannot, owing to the emphysema, be so well ascertained. The bowels are regularly relieved once or twice daily.

19th. - Much improved since last report. Mr. Fergusson since the 15th left the patient entirely to my care. He is up and dressed daily, and, aided by a stick, walks about his room. Emphysema almost removed, to be faintly felt about the pectorals and in the axillæ. Percussion shows the left side of the chest to be more resonant than the right side, due. no doubt, to the presence of air in the cavity. On applying the ear, there could be distinguished clear and distinct respiratory murmurs-this is over that portion of the chest corresponding to the middle and upper part of the lung. No murmurs could be detected in the base of the lung, and vocal resonance is far from clear. On the right sile the respiratory sounds are clear, puerile, and ratber prolonged; especially is this so at the apex of the lung. The cardiac sounds are clear, but rather faint. The pulsations of the heart's apex are not perceptible in the intercostal space. Hemipleria is gradually disappearing. The patient walks freely, aided by a stick, a distance of two or three miles withont being distressed. He can raise his left arm at the shoulder, and in a jerking manner advance the forearm; he has no influence over the flexors of the fingers. Temperature of the limb is increasing. Since the 11 th he has taken six grains of iodide of potassium three times daily in a bitter infusion, and a pill also every night, containing two grains each of mercury-with-chalk and compound ipecacuanha powder. The gums being now somewhat tender, he is to take the pill every alternate night.

June 13th. - The patient now resides in the country, and walks out daily. He expresses himself as enjoying as good health as ever has fallen to his lot. He can now raise his left hand to his head after a slight effort, and can with some ease extend the left arm at a right angle, and hold it thus for some seconds. Supination and pronation of the forearm can be performed, but not very ficely. To continue remedies, and exercise the left arm by the use of light weights. It is now ouly a question of time as to the entire recovery of the use of the limb. Jermyı-street, July, 1862 .

\section{A CASE OF}

\section{CHYLOUS URINE SUCCESSFULLY TREATED BY TINCTURE OF MURIATE OF IRON.}

$$
\text { BY G. C. DUTT, Esq., }
$$

SUPERINTENDENT OF THE BHOWANIPORE GOTERNMINT DISPENSART.

I BEG to forward the following particulars of a case of chylous urine which came under my notice some few weeks ago. The case is so far interesting that it presented several peculiarities which have not (as far as I know) been mentioned by authors who have written upon the subject :-
Sh'aghur, a male Hindoo, aged twenty four years, becamo an out-patient of the Bhowanipore Dispensary on the :55th of April last. He reported himself to have been suffering from chylous urine for four years, during which time he had been under several practitioners, and had taken a variety of medicines; but with very little benefit. As a last trial he came to me. On examining a specimen of his urine, it was found to be of a milky-white colour, thick, and full of coarnia. There was no pinkish tinge in it. I am sorry to say I did not examine it for sugar. The patient stated that at the commencement he had slight pain in the region of the right kidney; but that it was removed by a blister, which. however, dil not produce any effect on his morbid urine. He was dyspeptic; but his general health was good, and there was no evidence of any visceral disease or any local affection of the lymuhatic system. He had a slight attack of intermittent fever while under my treatment, and which was cured by a few doses of quinine. The peculiarities of this case were that the urine passed during the day was clear and free from chyle, while that voided during the night and in the morning was deeply loaded with it. At night micturition was frequent, and the urethra would sometimes get blocked up by coagula. He was very much subject to night emissions.

I treated him at first for dyspepsia, which did nothing more than improve his appetite. For this purpose $\mathrm{I}$ gave him tonics, antacids, \&c. I then tried gallic acid, in three-grain doses, three times a day, for five days; but with no better success. In fact, the symptoms were aggravated while under this treat. ment. I then resolved to try some prepara ions of iron, and accordingly ordered bim fifteen minims of tincture of muriate of iron, in an ounce of infusion of quassia, to be taken three times a day. Before he had taken the medicine for three days the improvement in his trine was marked, and at the end of the week it was entirely free from chyle. I kept him under observation for more than four weeks after this, and intermitted the use of the drug for a week, and am happy to say that his urine continued free from chyle. He was discharged on the $6 \mathrm{th}$ of June as cured.

I have very little to remak on this case, e specially as its pathology is involved in great obscurity. There are one or two points worthy of note: $W_{\text {as }}$ there any connexion as cause and effect between the dyspepsia and the chylous uine? I leave it to some of the numerous readers of THE LANCET to answer this question for me; but it is quite evilent that there could not have been any organic lesion excepting a slisht irritation of the right kilney at the outset. The night emissions may have been due to soine irritation existing at the mouth of the bladider; the patient remained subject to them long after the urine had ceased to present any trace of chyle in it.

Bhowanipore, Caleutta, 1862

\section{stirm}

\section{OF THE PRACTICF OF}

\section{MEDICINE AND SUR ERY IN THE}

\author{
HOSPTTALS OF LONDON.
}

Nulla est alia pro certo noscendi via, nisi quam plurimas et morborum et dissectionum historias, tam aliorum vroprias, collectas habere et inter se conparare.-Mongani. De Sed.et Cals. hIorb., lib. 14. Proœnium.

\section{ST. BAPTHOLOMEW'S HOSPITAL.}

COMPLETE AND UNYIELDING ADDECTION OF BOTH THIGHS; SECONDARY TALIPES FQUIYUS ; SUCCESSFULLY TREATED BY FORCIBLE EXTENSION.

(Under the care of Mr. CoOTE.)

ELIZABFTH L-- - aged seventeen, became the subject of a severe burn when about twelve years of age, in consequence of her clothes catching fire. She was more particularly burnt about the thighs, hips, back, and lower part of the abdomen, where numerons large cicatrices indicate the parts in which deep and extensive sloughs must have separated. On the outer surface of the left thigh there is a deep depression, leading to a cicatrix, the size of a five-shilling piece, and attached to 
the bone; but all the cicatrices have become soft and pliant, and as much as possible like the healthy skin. The limbs are warm, soft, and well dereloped; but the thighs are in a state of unyielding adduction, partially crossing one another. They are in a state of extreme extension as regards the pelvis (i. e., in a straight line as regards the trunk), and apparently immovably attached to the pelvis as by osseous union. There is free movement at the knee, but both feet are in the position usually termed talipes equinus. The girl, who possesses considerable personal attractions, stated that she had been confined to bed two years after the accident, and left her bed in her present condition. She can walk, but in a most ungainly way, resting on the fore part of her feet, the heels raised, the knees crossed, the thighs pressing one on the other. She throws the pelvis forward at each step. Mir. Coote remarked that this deformity, he thonght. proceeded from contractions about the hip.joints, the result of finlty nositions maintained during the two years confinement, while the large wounds were cicatrizing. There was no loss of nerve power nor deficiency of nutrition, the limbs being warm and of normal size. He expected to find the articulation of the hips uninjured. She had been under the care of several surgeons at different times.

On Saturday, June 25 th, Mr. Coote made forcible extension of both limbs, the patient's muscles having been rendered com. pletely relaxed by the administration of chloroform. He was assisted by Mr. Buller, and several visitors were present. (At this hospital, all cases involving personal exposure in the female are performed in the wards, and with as much respect to the patient's feelings as possible.) Both limbs were bent at the knee-joint, and were then forcibly abducted. The force was applied by the arms of the surgeons, and was maintained firmly, without jerking, but gradually inereasing, until at first a deepseated cracking sensation was felt in the left hip joint, then after about five minutes in the right; the sound was as if firm fibro-cartilage had been torn. In a few seconds after this all resistance suddenly ceased. No further extension was made, but both limbs came down at once to their normal position. Mr. Coote tried them gently, and found that in both movement at the hip.joint was complete.

The further treatment of the case will be effected by appa ratus to prevent recontraction and ensure free motion in the various joints. The patient was much excited with joy at the result, and at the present time is going on well

\section{ROYAL FREE HOSPITAL.}

CLINICAL REMARKS ON A CASE OF COMPOUND FRACTURE OF THE LEG, WITH PREVIOUS RACHITIS; EXCISION OF PROTRUDING PORTIONS OF THE TIBIA; RECOVERY, WITH A STRAIGHTENED LIMB.

\section{(Under the care of Mr. Gant.)}

S. B-, aged forty-eight, was admitted to the hospital with a compound fracture through the middle of the tibia and fibula, the result of direct violence. Two small wounds at the seat of fracture communicated with the bones. The tibia was much curved forward (as was that also of the other leg), owing to previous rachitis, so that the broken ends of this bone threatened to protrude. There was considerable contusion of the soft textures of the leg, which rapidly became swollen to a large size. The patient-a widow, without family-was of intemperate habits, and intoxicated at the time of the acciclent. Her stature was diminutive; and in early life, having been subject to rickets, several boues had been fractured-namely, those of the other leg and of both arms.

The limb was reduced and put up in the ordinary manner; but in a few days suppuration ensued at the seat of fracture, and the broken portions of the tibia protrucled. The patient's genera health was well sustained by food and her accustomed stimulants, with opiates nightly. Every chance was given for union, without further interference; and the proyress of the case showed that this result would have taken place, thus disprov ing the views formerly held by authorities, and still lingering in systematic works on surgery-to the effect that intemperance and rickets are unfavourable to the union of fracture. Bu in the present case the arched shape of the tibia disarranged the even and quiescent apposition of the fragments, and per. petuated their protrusion.

Under these circumstances-six weeks having elapsed with out union, although the patient's general health was much im.
proved-Mr. Gant considered it advisable to excise the broken ends of the tibia, and sufficiently so to enable him to reduce the leg to a better shape than before the accident. This proceening - next to saving the limb intact-was a more conserva. tive measure than amputation. Failing to accomplish the first object, this operation offered itself as a measure intervening, so to sueak, between that and saving the life at the cost of the limb. Accordingly, Mr. Gant enlarged the wound sufficiently to freely expose the portions of bone. The anterior tibial artery was sean beating along their onter aspect, and was avoided. The leg being then sufficiently bent at the seat of fracture to evert the fractured ends, they were sawn off, each to the extent of about an inch. The leg was then reduced to a far straighter shape than before this operation, and the case was afterwards treated as an ordinary compound fracture. In the course of two months firm osseous union had ensued, and the patient was discharged in good health, with a sound limb about two inches shorter than its fellow. A tigh-heeled shoe enabled her to walk with comfort and facility.

Nr. Gant observed that this operation has the same conservative relation to fracture that excision bas to disease of a joint; either operation being a compromise between saving the limb in tact and its sacrifice by amputation. Whenever fracture was irreducible, or incapable of being kept reduced, owing to deformity of the bone; in compound fracture with protrusion and contusion of the broken ends of bone; in fracture of dis. eased bone; and in some cases of obstinate ununited fracture, excision of the broken ends might be resorted to, and practised with success

\section{KING'S COLLEGE HOSPITAL.}

\section{CLINICAL REMARKS ON A CASE OF CANCER OF THE} UTERUS.

(Under the care of Dr. TANNER.)

Mrs. A. P__, sixty-two years of age, was admitted as an out-patient in July, 1S60. She was thin, weak, and care-worn; pain and poverty had traced deep lines on her face. The history she gave was as follows:- She has had ten pregnancies and nine children. The last child was born at the full term on November 21st, 1840; has not been pregnant since. Usually been in bad health, without being actually ill. There is no hereditary tendency to any disease that she can remember. First began to feel very weak and low about fifteen months ago, but had no advice until the commencement of the year. At this time she had a slight attack of flooding, with bearing. down pain. Since then she has suffered chiefly from backache, gnawing pain at the lower part of the stomach, and an offensive watery discharge. Appetite bad; has very little sleep at night, and is very responding.

On examination, the uterus was found low down in the cavity of the pelvis, and completely fixed. The lips were destroyed by a larce malignant ulcer, the edges of which were hard and fungeil. There was a copious, very offensive, watery discharge, and the examination produced pain, with a slight hamorrhage. In the treatment of this case there appeared to be three prominent indications. These were, to keep the dis. eased organ as quiet as possible, avoiding all local treatment and examinations; to maintain the general health by helping her to procure good nourishing food, and by taking care to check any hæmorrhage directly it set in; and to relieve her pains as far as could be done without impairing the functions of the stomach, \&c. Acting on these principles, the only medicines administered have been gallic acid, with the compound tincture of cinnamon, and sulphuric acid whenever there was any discharge of blood, together with the daily employment of morphia. Had it been certain that a deodorizing injection could have been carefully and gently used, a solution of the permanganate of potash wonld have been ordered; as it was, Dr. Tanner felt convinced that any injection would do much more harm than good. Under this simple plan of treat. ment the patient's healch is now (July 11 th, 1862 ) in such an improved atate, that she can walk two miles at least without fatigue. The appetite is good; the pain is only severe when she omits taking half a grain of morphia thrice daily; her bowels act every second dar, and she sleeps well at nimbt. She is thin, however, and has the appearance of one suffering from malignant disease. The condition of the uterus is much the same as it was, except that the discharge is less, and the tendency to hæmorrhage has much diminished. It is strange that the ulceration seems to be stationary, being neither better nor worse than it was two years ago. 